\title{
TRANSFORMANDO ATIVIDADES PRÁTICAS EM EXPERIMENTOS: UMA REFLEXÃO A PARTIR DE INTERVENÇõES PRÁTICAS NO ENSINO DE CIÊNCIAS
}

\author{
TRANSFORMING PRACTICAL ACTIVITIES INTO EXPERIMENTS: A REFLECTION \\ BASED ON PRACTICAL INTERVENTIONS IN SCIENCE TEACHING
}

Simão Dias Vasconcelos ${ }^{1}$, Kênio Erithon Cavalcante Lima ${ }^{2}$

Recebido: março/2020 Aprovado: dezembro/2020

\begin{abstract}
Resumo: Atividades práticas descritas como experimentos em livros e sites didáticos de Ciências frequentemente possuem um papel demonstrativo, pois não operacionalizam procedimentos metodológicos associados a um experimento per se. Neste artigo, nós discutimos a terminologia e a metodologia intrínseca a um experimento didático tendo como ponto de partida atividades frequentemente expostas em livros e sites didáticos, exemplificando situações em que atividades assumem caráter estritamente demonstrativo e/ou observacional. Apontamos diferenças contextuais e metodológicas entre diferentes procedimentos associados à prática investigativa e discutimos as implicações para o processo de aprendizagem. Por meio de exemplos associados ao ensino de conteúdos de Física, Química e Biologia, sugerimos caminhos para que atividades de demonstração possam assumir um caráter desafiador e de maior complexidade para o aprofundamento da aprendizagem. Por fim, discutimos implicações de mudanças conceituais e metodológicas nas atividades para o ensino das Ciências.
\end{abstract}

Palavras chave: Ensino de Ciências, experimentação, ensino fundamental.

\begin{abstract}
Practical activities described as experiments in science textbooks and websites often have a demonstrative role, as they do not operationalize methodological procedures associated with an experiment per se. In this article, we discuss the terminology and methodology intrinsic to a didactic experiment taking as a starting point activities frequently exposed in didactic books and websites, exemplifying situations in which activities are strictly demonstrative and / or observational. We point out contextual and methodological differences between different procedures associated with investigative practice and discuss the implications for the learning process. Through examples associated with the teaching of Physics, Chemistry and Biology contents, we suggest ways for demonstration activities to take on a challenging and more complex character to deepen learning. Finally, we discuss the implications of conceptual and methodological changes in activities for science teaching.
\end{abstract}

Key words: Science teaching, experimentation, elementary level.

\section{Introdução}

A importância das atividades práticas no ensino de Ciências é amplamente reconhecida em estudos que evidenciam como o desenvolvimento da capacidade investigativa e do pensamento científico do estudante é impulsionado, de modo sistematizado, pela aproximação do objeto de estudo quando mediado pela experimentação (HAEFNER; ZIMBAL-SAUL, 2004; KOPONEN; MÄNTYLÄ, 2006). Por meio da experimentação, aplicada no ensino das Ciências da

1 ID ORCID iD 0000-0002-8722-0836- PhD, University of Oxford. Professor Titular, Universidade Federal de Pernambuco (UFPE), Avenida Professor Moraes Rego, s/n, 50.670-420, Recife - PE, Brasil. E-mail: simao.vasconcelosfo@ufpe.br

2 ID ORCID iD 0000.0001-7434-7013, Doutor, Universidade Federal de Pernambuco (UFPE). Professor Associado, Universidade Federal de Pernambuco, Centro Acadêmico de Vitória (CAV-UFPE). Rua Alto do Reservatório, s/n, 55.608-680, Vitória de Santo Antão -PE, Brasil. E-mail: kenio.lima@ufpe.br 
Natureza, o estudante tem oportunidade de, entre outras competências, formular e testar hipóteses, desenvolver estratégias para coleta de dados, obter respostas a questionamentos, investigar e interpretar influências externas aos fenômenos naturais, correlacionando respostas à(s) teoria(s) (HODSON, 1988; ZÔMPERO; LABURÚ, 2011; CARVALHO, 2018; SASSERON, 2018).

Da mesma forma, o processo de aprendizagem baseado na experimentação oportuniza novos saberes aos estudantes ao aproximarem-nos de situações e percursos característicos da construção de conhecimentos científicos por meio da pesquisa "real" (STRIEDER; WATANABE, 2018). Nas vivências didáticas proporcionadas pelo ensino por experimentação, o estudante melhor compreenderá que o conhecimento científico não se limita a laboratórios sofisticados, mas pode ser construído a partir de questionamentos próximos à sua realidade, em sala de aula, em parceria com professores e colegas (BASSOLI, 2014; NASCIMENTO; GOMES, 2018; STRIEDER; WATANABE, 2018). Em síntese, o estudante perceberá que as respostas aos problemas surgem de questionamentos logicamente embasados, e rigorosamente interpretados, a fim de conhecer a realidade ao seu redor.

Ao historicizarmos o ensino com experimentação, referências à inserção da atividade experimental em propostas de ensino de Ciências no Brasil têm sido descritas desde a década de 1950 (NARDI, 2005; LIMA, 2015). A partir da década de 1980, pesquisadores brasileiros, influenciados por correntes teóricas psicológicas e pedagógicas que embasavam tendências de ensino em outros países, intensificaram a discussão sobre perspectivas para entender o ensino de Ciências como um processo de caráter investigativo, superando limitações associadas ao desenvolvimento de técnicas desprovidas de significados ao contexto dos estudantes (KRASILCHIK, 2004; NARDI, 2005; CARVALHO, 2018).

A adoção de procedimentos ditos experimentais no ensino de Ciências despertou questionamentos sobre a validade dos modelos de atividades práticas e sua aplicabilidade na construção dos sentidos e na relação social do aprendiz que experimenta (HAEFNER; ZIMBALSAUL, 2004). Questiona-se, por exemplo, se o que se está sendo realizado pode ser considerado experimento quando na verdade frequentemente realizam-se atividades que negligenciam possibilidades de o estudante construir pressupostos necessários da práxis investigativa tratando-se de um "exercício de atividades práticas que se esgotam em si mesmas, assumindo um caráter puramente empirista" (VENDRUSCOLO, 2008, p. 102). Ou seja, as atividades práticas que se restringem a observações e comprovações de teorias pré-exploradas "aparecem como verdades prontas e definidas, não se caracterizando, portanto, como ações investigativas e de cunho científico" (VENDRUSCOLO, 2008, p. 102).

No ensino básico, a experimentação se apresenta "de maneira bastante diversa quanto ao significado que essas atividades podem assumir em diferentes contextos e em diferentes aspectos" (ARAÚJO; ABIB, 2003, p. 177). Se, por um lado, esta pluralidade representa oportunidades de inovação, por outro, muitos professores ainda associam a experimentação aos kits e roteiros que limitam o procedimento didático-metodológico, de forma a prédeterminar os resultados e conclusões que o estudante deverá construir (LIMA, 2015). Tal visão desperdiça a oportunidade de estimular no estudante possibilidades de correlacionar o senso comum com o conhecimento científico para formar, reformular, adaptar e aplicar distintas 
concepções do mundo, possibilitando que o sujeito da aprendizagem confronte e redefina sua experiência diante dos objetos de estudo (BACHELARD, 2007).

$\mathrm{Na}$ epistemologia da experimentação aplicada ao ensino, o educador é desafiado a "colocar a cultura científica em estado de mobilização permanente, substituir o saber fechado e estático por um conhecimento aberto e dinâmico, dialetizar as variáveis experimentais, oferecer enfim à razão razões para evoluir" (BACHELARD, 2007, p. 24). As complexidades desta construção teórico-metodológica contrapõem-se à visão de que o experimento deve servir unicamente para verificação ou refutação do conhecimento. Isto porque, ao perpetuar uma aquisição imediatista e linear de conhecimentos, este entendimento desconsidera o sujeito social constituído de conflitos e barreiras, e ignora a necessidade das dúvidas aos saberes prévios, e de se evidenciar acontecimentos particulares à situação experimentada (BASSOLI, 2014; NASCIMENTO; GOMES, 2018). Neste sentido, construímos nosso percurso na defesa da experimentação como estratégia de ensino que pode superar concepções de que a aprendizagem deve partir do zero para apropriar o outro de conhecimentos científicos.

O reconhecimento da importância da experimentação no ensino de Ciências resultou em transformações no material didático, especialmente com o Programa Nacional do Livro Didático. Gradativamente, os livros passaram a incluir uma crescente variedade de atividades práticas com diferentes níveis de complexidade e autonomia - muitas delas classificadas como experimentação. Percebeu-se de imediato um avanço teórico metodológico em relação às primeiras propostas de implantação de kits de experimentação da década de 1960 (NARDI, 2005; LIMA, 2015), o que desencadeou, desde então, diversas leituras construídas a partir da necessária correlação conceitual e a pertinência pedagógica da atividade proposta no livro didático (LD) e a possibilidade de o estudante interferir ativamente no processo de construção de novos conhecimentos científicos (WESENDONK; RODRIGUES; TERRAZAN, 2011). Entretanto, a maioria dos questionamentos parece negligenciar um eixo crucial desta reflexão: a discussão semântica do que se considera experimento, as consequências derivadas de inadequações em sua apropriação pelo estudante e pelo professor e a perda das possibilidades de aprendizagem que a experimentação pode oportunizar ao estudante que participa da atividade.

Em referência à Base Nacional Comum Curricular (BNCC) (BRASIL, 2018), as atividades baseadas na experimentação orientam que o processo educacional estimule os estudantes a, progressivamente, participar de atividades práticas em cooperação com professores e demais colegas, características de procedimentos que construam resultados a serem compartilhados coletivamente, sendo esses preceitos favoráveis para um ensino mais investigativo (SASSERON, 2018). Assim, ao tratarmos de experimentos, torna-se oportuno fazermos algumas conceituações. De modo simplificado, um experimento pode ser definido como um ensaio científico destinado à verificação de um fenômeno físico e/ou natural que desencadeia, em seu ato, a experimentação (FERREIRA, 2009). $O$ ato de experimentar para a construção de saber científico pressupõe aplicar arcabouços teóricos coletivamente chamados de "método científico" para investigar fenômenos sob condições controladas, e, assim, aumentar o conhecimento sobre os fenômenos para elaboração das leis gerais que os regem.

Para Abbagnano (1998), a reconstrução e assimilação do conhecimento, com novas informações postas à prova, oportuniza ao aprendiz ampliar sua experiência, pois esta será uma 
das consequências do experimento, do desejo de experimentar para construir saberes. A experiência, por sua vez, é o conhecimento que pode ser apropriado pelo homem. $\mathrm{O}$ autor também defende a compreensão de experimento como "uma experiência que diz respeito a fatos naturais que só acontecem quando intervém nossa ação" (p. 414) e/ou como "uma observação provocada com o fim de dar origem a uma ideia" (p. 415), a um conhecimento.

Entre pesquisadores das Ciências da Natureza, é possível definir experimento como:

Uma atividade em que as variáveis são manipuladas de maneira pré-estabelecida e seus efeitos suficientemente controlados pelo pesquisador para observação do estudo. Este método desempenha dupla função: a) para descobrir conexões causais, e b) para atingir a demonstrabilidade (FACHIN, 2017, p. 40).

Para Weiss (1962), a relação entre experimento e experiência, apesar de íntima, pode ser diferenciada, pois:

Experiência significa familiaridade com os acontecimentos do mundo. É nosso registro cumulativo de julgamentos e suposições que formamos consciente ou inconscientemente a partir de incontáveis observações, impressões e comparações. Experimentos, em contraste, são testes objetivos acerca da validade factual das nossas suposições (...). A experiência nos faz assumir e esperar relações entre as coisas na natureza, mas é tarefa do experimento verificar essas premissas e expectativas. A experiência nos direciona e guia os experimentos, e os experimentos, por sua vez, confirmam, ampliam ou modificam o conteúdo da experiência (WEISS, 1962, tradução dos autores).

Sob esta ótica, o experimento seria a ação, a práxis, enquanto a experimentação seria a abstração deste processo, a categorização deste procedimento metodológico. Ao estimular a experimentação no ensino de Ciências, por exemplo, o professor pode lançar mão de vários experimentos. Esta concepção transcende o empirismo baseado unicamente na percepção e reconhecimento da realidade por meio dos sentidos. Dependendo do autor, a definição de experimento pode ser ainda mais específica: um experimento envolveria uma ação deliberada de um pesquisador (tratamento) imposto a um sistema de forma que a resposta a este tratamento possa ser observada e/ou medida em comparação às condições de ausência do tratamento - ou a um conjunto de características iniciais diferentes (controle). Tratamento e controle poderiam ser observados simultaneamente ou se construiria um protocolo de modo a comparar o antes (controle) com o depois (a partir da aplicação de um tratamento) (FORD, 2000). Neste sentido, Wesendonk, Rodrigues e Terrazan (2011) discutem critérios para definir uma atividade didática baseada em experimentos, como a manipulação de dados numéricos, o tipo de recurso utilizado, o grau de autonomia e participação do estudante e a função educativa da atividade, entre outros (Tabela 1). Há, contudo, outros procedimentos associados à pesquisa científica que não se caracterizam como experimentação, alguns dos quais podem ser utilizados por professores do ensino básico para apresentação, consolidação e contextualização do conteúdo trabalhado (Tabela 1). A Tabela 1 estabelece uma comparação sintética entre o que caracteriza um experimento e outros procedimentos associados à pesquisa científica e que podem ser realizados no ensino das Ciências da Natureza com resultados também significativos ao processo de aprendizagem dos estudantes. 
Tabela 1. Exemplos de atividades práticas envolvendo diferentes processos metodológicos que podem ser utilizadas pelo professor de Ciências.

\begin{tabular}{|c|c|c|c|}
\hline $\begin{array}{l}\text { Atividade } \\
\text { Prática }\end{array}$ & $\begin{array}{l}\text { Conceituação / } \\
\text { Características }\end{array}$ & $\begin{array}{l}\text { Principais Processos } \\
\text { Metodológicos Envolvidos }\end{array}$ & Exemplos \\
\hline Observação & $\begin{array}{l}\text { Trata-se do estudo } \\
\text { detalhado dos fenômenos, } \\
\text { se possível, aproximando-se } \\
\text { ao que ocorre na natureza. } \\
\text { A partir desta, busca-se } \\
\text { realizar descobertas, } \\
\text { descrever e explicar } \\
\text { fenômenos e colaborar na } \\
\text { construção de leis e teorias. }\end{array}$ & $\begin{array}{l}\text { Planejamento para } \\
\text { observação meticulosa e } \\
\text { descrição fiel de } \\
\text { fenômenos. Estimula o ato } \\
\text { de registrar, comparar, } \\
\text { extrapolar, para } \\
\text { posteriormente fortalecer } \\
\text { a teoria em estudo. }\end{array}$ & $\begin{array}{l}\text { Observação dos astros, } \\
\text { de insetos no pátio da } \\
\text { escola, da germinação de } \\
\text { uma planta, das } \\
\text { propriedades do ar, das } \\
\text { características do solo, } \\
\text { da poluição no bairro etc. }\end{array}$ \\
\hline Levantamento & $\begin{array}{l}\text { Forma a base das pesquisas } \\
\text { de opinião, e normalmente } \\
\text { lida in loco com os } \\
\text { participantes do fenômeno } \\
\text { estudado. Neste caso, o } \\
\text { estudante pode aplicar } \\
\text { questionários e realizar } \\
\text { entrevistas etc. Na Biologia, } \\
\text { o levantamento tem } \\
\text { significado de "inventário" } \\
\text { para conhecer os seres vivos } \\
\text { em um espaço geográfico. }\end{array}$ & $\begin{array}{l}\text { Elaboração } \\
\text { instrumentos de coleta de } \\
\text { informações (roteiros de } \\
\text { questionário e entrevista) } \\
\text { ou, se autorizados, de } \\
\text { seres vivos e minerais. } \\
\text { Estimula uma abordagem } \\
\text { quantitativaras } \\
\text { resultados, dos } \\
\text { explicações do fenômeno } \\
\text { ao estabelecer relações de } \\
\text { causa e efeito. }\end{array}$ & $\begin{array}{l}\text { Caracterização do perfil } \\
\text { dos estudantes da escola, } \\
\text { de suas opiniões sobre } \\
\text { temas diversos, } \\
\text { identificação de ações de } \\
\text { cuidado dos moradores } \\
\text { do bairro (coleta do lixo, } \\
\text { uso racional da água). No } \\
\text { sentido de "inventariar": } \\
\text { diversidade de plantas e } \\
\text { insetos nas praças e no } \\
\text { pátio da escola. }\end{array}$ \\
\hline Demonstração & 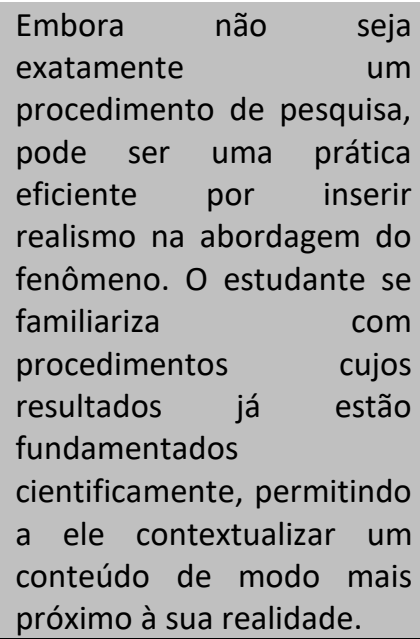 & $\begin{array}{l}\text { Estimula o estudante a } \\
\text { seguir roteiros ou } \\
\text { procedimentos que } \\
\text { fundamentaram teorias } \\
\text { comprovadas. O professor } \\
\text { efetua a atividade, } \\
\text { manipulando as variáveis } \\
\text { para os demais } \\
\text { participantes o } \\
\text { acompanharem } \\
\text { processo, interferindo e } \\
\text { conferindo seus resultados } \\
\text { como previsto para avaliar } \\
\text { se sua participação teve } \\
\text { sucesso. }\end{array}$ & $\begin{array}{l}\text { Construção de modelos } \\
\text { didáticos que simulam } \\
\text { fenômenos biológicos, a } \\
\text { exemplo, do modelo } \\
\text { didático de bexigas } \\
\text { dentro de um recipiente } \\
\text { fechado, conectadas por } \\
\text { tubos, cujo enchimento } \\
\text { simula o movimento de } \\
\text { entrada e saída de ar nos } \\
\text { pulmões. }\end{array}$ \\
\hline
\end{tabular}

Fonte: Autores

O debate sobre o ensino de Ciências por investigação (CARVALHO, 2018) será enriquecido por uma reflexão sobre como uma atividade prática não experimental ${ }^{1}$ (MILLAR, 2004) pode ser transformada em experimentação. Tomando como ponto de partida a frequência com que algumas atividades encontradas em livros didáticos e sites educativos - muitas das quais de

${ }^{1}$ Utilizamos "atividade prática" para qualquer atividade de ensino e aprendizagem em que algum ponto envolve os alunos na observação ou manipulação de objetos e materiais de estudo, independentemente da localização (MILLAR, 2004). 
caráter demonstrativo - são comumente classificadas como experimentos, consideramos relevante refletir sobre a pertinência do uso do termo "experimento" em situações que claramente não se configurariam mais como tal.

Propusemos, então, um questionamento propulsor para nossa reflexão: Que possibilidades são possíveis identificar para complexizar atividades práticas a fim de incorporar procedimentos metodológicos associados à experimentação? Especificamente, neste estudo, temos como objetivo demonstrar possibilidades de transformação de práticas de observação/ demonstração em experimentação, por meio de exemplos frequentemente encontrados em livros didáticos e sites com propostas de atividades práticas educacionais. Por objetivos complementares, destacamos i) propor uma reflexão sobre o caráter "experimental" de atividades práticas descritas em livros didáticos de Ciências e em sites com propostas de atividades práticas de aspecto educativos e ii) levantar questionamentos sobre os aspectos metodológicos e pedagógicos envolvidos na conceituação de atividades como "experimentos".

\section{Procedimentos Metodológicos}

Quanto à sua natureza e objetivos, este estudo caracteriza-se como uma pesquisa descritiva e exploratória quanto à sua natureza e abordagem (GRAY, 2012). Quanto ao procedimento metodológico utilizado, trata-se de uma pesquisa documental, tendo como fonte primária material já disponível, a ser analisado sob uma nova perspectiva com problema de pesquisa original (GRAY, 2012). Pesquisamos em 16 livros didáticos de quatro coleções voltadas para o Ensino Fundamental II e 12 sites e blogs educativos a proposição de atividades práticas para realização na escola, em laboratório ou sala de aula. Cada atividade foi escrutinizada de acordo com a abordagem até sua categorização como um (ou mais) procedimento metodológico construído a partir de referencial teórico (LIMA, 2015; PÉREZ; FURMAN, 2016; CARVALHO, 2018). Dentre as atividades examinadas, algumas apresentavam-se descritas como experimentos pelas fontes consultadas. Durante esta leitura crítica foram selecionadas atividades que se destacam por sua presença frequente - com pequenas variações, por sua relativa facilidade de execução, e por serem passíveis de adequação a uma formatação experimental após sofrerem modificações.

O objetivo da leitura crítica não foi apontar erros nas orientações e interpretações do arcabouço metodológico, mas sim questionar a natureza da atividade e a sua possibilidade de ser modificada para atividades práticas experimentais. Dentre uma listagem de atividades práticas disponíveis para o ensino de Ciências, optamos por aprofundar sua complexidade, aproximando-as do caráter experimental per se com sugestões de variáveis e abordagens, o que vem a enriquecer o processo de aprendizagem dos estudantes.

Tivemos como eixo norteador orientações preconizadas nas Competências para a área de Ciências da Natureza descritas na BNCC, a qual, especificamente na Competência \#2 prescreve:

Compreender conceitos fundamentais e estruturas explicativas das Ciências da Natureza, bem como dominar processos, práticas e procedimentos da investigação científica, de modo a sentir segurança no debate de questões científicas, tecnológicas, socioambientais e do 
mundo do trabalho, continuar aprendendo e colaborar para a construção de uma sociedade justa, democrática e inclusiva (BRASIL, 2018, p.320)

Como critérios para seleção de atividades aptas à modificação da metodologia para adequar-se aos princípios que definem um experimento, priorizamos práticas factíveis, de baixo custo, seguras, de execução relativamente fácil, sem necessidade de equipamentos especializados, respeitando a realidade da maioria das escolas de ensino fundamental do país.

\section{Resultados e Discussão}

O que é considerado "experimento" nas propostas de atividades práticas de Ciências? Uma leitura crítica em LD de Ciências do Ensino Fundamental II aprovados nas avaliações do PNLD 2017, e em sites com atividades práticas educativas revela variações na nomenclatura e em aspectos conceituais ao apresentarem atividades práticas como "experimento". Frequentemente, seções foram intituladas "Vamos fazer um experimento?", "Experimentando", "Agora é sua vez de fazer um experimento", as quais se apresentavam com o propósito de executar práticas não experimentais para confirmar fatos, normalmente apropriando-se de informações visuais e conceitos previamente trabalhados de forma teórica. A atividade descrita como experimentação assumia um sentido de constatação, com o propósito de "verificar a validade de determinadas previsões teóricas" (ARAÚJO; ABIB, 2003, p. 181), atrelada a um roteiro previamente estabelecido que limitava a ação do agente, pois apresentava-se como demonstração ou observação, como destacado em estudos anteriores (CACHAPUZ; PRAIA; JORGE, 2004; BASSOLI, 2014), o que vem a diferir dos novos pressupostos defendidos em textos científicos (LIMA, 2015) e em documentos oficiais (BRASIL, 2018).

Percebe-se nas coleções e sites consultados uma supervalorização da ideia de que esteja se realizando, de fato, um experimento. Uma das possíveis razões para o uso enfático do termo experimento/ experimentação poderia ser pela necessidade de atender às exigências dos editais do PNLD para Ciências no ensino fundamental. Por meio dos seus critérios de avaliação, o Ministério da Educação classifica coleções que atendem exigências para o desenvolvimento de atividades experimentais factíveis, com resultados confiáveis e interpretação teórica correta (BRASIL, 2016), condizentes com os critérios descritos a seguir:

3.1.11. As obras didáticas deverão incluir referências a outros componentes curriculares da mesma área e também de outras áreas de conhecimento, bem como conduzir os alunos a atividades de experimentação e situações reais para consolidação da aprendizagem.

3.1.12. As referências e atividades de experimentação, previstas no subitem anterior, terão caráter eliminatório e estão definidas no Anexo III deste edital. (p. 2).

Por sua importância no percurso histórico do ensino das Ciências da Natureza, a valorização do conhecimento obtido "experimentalmente" é defendida por vários pesquisadores, a exemplo da afirmação a seguir:

Por tradição, a reprodutibilidade dos resultados experimentais e a consistência com os 'fatos observáveis' são considerados os critérios pelos quais as teorias científicas são apreciadas. Como consequência, invariavelmente os currículos escolares de Ciências investem 
enormemente na crença na capacidade de observação e experimentação para proporcionar dados confiáveis na tomada de decisões inequívocas sobre a validade das teorias (HODSON, 1992, p. 546, tradução dos autores).

A rotulação de experimento para atividades práticas generalizadas teria por objetivo aproximar o cotidiano das crianças do exercício da profissão de cientistas? Estudo conduzido na Irlanda evidencia uma visão popularizada de crianças sobre Ciência, as quais, ao serem questionadas sobre o que os cientistas fazem, apresentavam como respostas mais frequentes que cientistas são pessoas que se utilizam de sua imaginação para fazer experimentos (MURPHY et al., 2011). Confirmando esta tendência, Oliveira (1992) nos chama a atenção de que a experimentação tem sido encarada como uma "fórmula" metodológica para enfrentar o problema da baixa aprendizagem em Ciências, o que pode levar a uma leitura superficial dos procedimentos envolvidos e com isso negligenciar possibilidades de inserir complexidade no ensino das Ciências.

Observamos que atividades práticas caracterizadas como experimento em livros e sites seriam, na verdade - segundo as normativas do método científico - definidos como procedimentos afins (observação, demonstração), mas não como experimentos, por não evidenciarem que variável(is) estaria(m) sendo manipulada(s) (Tabela 2). Outro aspecto observado é a ênfase na visualização de fenômenos, com atuação passiva dos estudantes, como se esta atitude fosse suficiente para construir conhecimento e capacitá-los a discutir conceitos. Por exemplo, em uma das atividades corriqueiramente explorada em LD e sites, o "experimento" assim definido propõe-se a investigar as propriedades do solo, sugerindo que o estudante mergulhe dois copos contendo duas amostras de solo em diferentes estados de compactação em uma bandeja com água, sendo uma das amostras de solo não compactado e a outra após sofrer compactação. A princípio, a atividade propõe que o estudante observe (constate) a formação de maior quantidade de bolhas de ar saindo do copo com solo não compactado devido à maior presença de ar entre as granulações do solo, sem que promova a formulação de hipóteses sobre o motivo para o surgimento dos gases, o qual depende de característica da granulação dos solos e dos espaços existentes entre as partículas sólidas. Sob esta ótica, evidenciam-se inadequações metodológicas caso a atividade seja definida como experimentação, baseando-se na apresentação da atividade sem a devida construção de hipóteses e questionamentos sobre o fenômeno diante das observações. Nesta situação, dificilmente o estudante expressaria saberes além da simples observação, sem a percepção de variáveis, o registro quantitativo dos fenômenos, e a relação dos conhecimentos construídos com as teorias vigentes, inerentes a um procedimento experimental (PÉREZ; FURMAN, 2016). 
Tabela 2. Breve descrição de atividades práticas frequentemente definidas como experimento" em livros didáticos e sites educativos com sua correspondente classificação de acordo com os princípios da Metodologia Científica.

\begin{tabular}{|c|c|c|c|}
\hline Título & Descrição da Atividade & $\begin{array}{l}\text { Considerada Experimento } \\
\text { Stricto Sensu? }\end{array}$ & $\begin{array}{l}\text { Implicações para a } \\
\text { Construção do } \\
\text { Conhecimento }\end{array}$ \\
\hline $\begin{array}{l}\text { Reciclagem } \\
\text { de papel }\end{array}$ & $\begin{array}{l}\text { A atividade sugere a coleta } \\
\text { de jornais e outros tipos de } \\
\text { papel, que serão picotados } \\
\text { e postos em água. Na } \\
\text { sequência, o material é } \\
\text { triturado em um } \\
\text { liquidificador e depois } \\
\text { passado por uma peneira } \\
\text { para a produção de novo } \\
\text { papel. }\end{array}$ & $\begin{array}{l}\text { Esta atividade prática } \\
\text { omite o resgate do } \\
\text { conhecimento prévio, a } \\
\text { formulação de hipóteses, a } \\
\text { coleta rigorosa dos dados, } \\
\text { nem explica fenômenos. }\end{array}$ & $\begin{array}{l}\text { A atividade estimula } \\
\text { concepções necessárias à } \\
\text { formação conceitual dos } \\
\text { estudantes, utilizando a } \\
\text { reciclagem como postura } \\
\text { conservacionista. Assume- } \\
\text { se um papel ativo e gera } \\
\text { um produto, mas sem } \\
\text { construir e/ou validar uma } \\
\text { teoria. }\end{array}$ \\
\hline $\begin{array}{l}\text { Percepção da } \\
\text { Temperatura }\end{array}$ & $\begin{array}{l}\text { A atividade se propõe a } \\
\text { demonstrar a percepção da } \\
\text { variação da temperatura } \\
\text { pelo tato. Inicialmente, } \\
\text { colocam-se as mãos em } \\
\text { recipientes com água com } \\
\text { temperaturas diferentes } \\
\text { (morna e gelada); em } \\
\text { seguida, colocam-se as } \\
\text { mãos em água a }\end{array}$ & $\begin{array}{l}\text { A prática não apresenta } \\
\text { uma proposta } \\
\text { investigativa, apenas } \\
\text { comprobatória, de que o } \\
\text { tato apresenta como uma } \\
\text { de suas propriedades } \\
\text { perceber a variação da } \\
\text { temperatura. }\end{array}$ & $\begin{array}{l}\text { Contribui por reforçar a } \\
\text { teoria da percepção do } \\
\text { tato; no entanto, mesmo } \\
\text { tendo seu valor como } \\
\text { instrumento de formação } \\
\text { de conceitos, reforçando } \\
\text { ensinamentos abordados } \\
\text { teoricamente, não caberá } \\
\text { a tal atividade a concepção } \\
\text { de uma experimentação. }\end{array}$ \\
\hline
\end{tabular}
para perceber a variação térmica.

\begin{tabular}{|c|c|c|c|}
\hline $\begin{array}{l}\text { Crescimento } \\
\text { vegetal }\end{array}$ & $\begin{array}{l}\text { Consiste em observar o } \\
\text { crescimento dos vegetais } \\
\text { em direção à luz. Ao se } \\
\text { colocar uma semente em } \\
\text { um recipiente com areia e } \\
\text { água dentro de uma caixa } \\
\text { com uma abertura lateral, } \\
\text { espera-se que o estudante } \\
\text { observe que a planta } \\
\text { crescerá em sentido da } \\
\text { abertura, por onde a luz } \\
\text { penetra. }\end{array}$ & $\begin{array}{l}\text { A atividade desconsidera } \\
\text { pontos fundamentais de } \\
\text { um experimento, ao } \\
\text { ignorar variáveis (ex. } \\
\text { suprimento de água), ou } \\
\text { não alertar para resultados } \\
\text { inesperados, que fazem } \\
\text { parte da natureza da } \\
\text { própria investigação (Ex.: a } \\
\text { planta poderia morrer caso } \\
\text { a abertura da luz fosse } \\
\text { muito pequena). }\end{array}$ & $\begin{array}{l}\text { A atividade fortalece a } \\
\text { percepção dos estudantes } \\
\text { de que os vegetais } \\
\text { possuem uma relação } \\
\text { direta e dependente daluz. } \\
\text { Dependendo do interesse } \\
\text { e do nível da turma, a } \\
\text { estratégia pode se } \\
\text { desdobrar para dar } \\
\text { suporte ao estudo dos } \\
\text { conceitos da fotossíntese e } \\
\text { dos fatores que afetam } \\
\text { reações químicas. }\end{array}$ \\
\hline Solubilidade & $\begin{array}{l}\text { A atividade propõe a } \\
\text { observação das } \\
\text { propriedades de } \\
\text { solubilidade de materiais } \\
\text { diferentes, como sal, fubá e } \\
\text { areia. Sugere a distribuição } \\
\text { da água em três copos, um } \\
\text { para cada produto, } \\
\text { agitando-os com um } \\
\text { bastão, levando os } \\
\text { estudantes a observar os } \\
\text { processos de solubilidade } \\
\text { em cada situacão. }\end{array}$ & $\begin{array}{l}\text { A atividade é apresentada } \\
\text { como uma observação, } \\
\text { tendo como variável a } \\
\text { propriedade } \\
\text { solubilidade. Apresenta } \\
\text { critérios e uma } \\
\text { metodologia estruturada } \\
\text { de forma a permitir } \\
\text { inferências sobre o } \\
\text { conceito de solubilidade. }\end{array}$ & $\begin{array}{l}\text { Instiga o estudante a } \\
\text { compreender o conceito } \\
\text { de solubilidade, propondo } \\
\text { a "experimentação" sem } \\
\text { controle de variáveis. } \\
\text { Explora a interação sólido- } \\
\text { água e as propriedades da } \\
\text { matéria, apresentando } \\
\text { questionamentos possíveis } \\
\text { de fortalecer a percepção } \\
\text { do estudante sobre as } \\
\text { variáveis abordadas. }\end{array}$ \\
\hline
\end{tabular}




\begin{tabular}{|c|c|c|c|}
\hline $\begin{array}{l}\text { Propriedades } \\
\text { do ar }\end{array}$ & $\begin{array}{l}\text { Para reforçar o conceito de } \\
\text { que o ar é matéria, propõe- } \\
\text { se um "experimento" em } \\
\text { que se equilibram balões de } \\
\text { festa cheios com ar em } \\
\text { extremidades opostas de } \\
\text { uma vareta; a seguir, um } \\
\text { dos balões é estourado, } \\
\text { ocasionando uma } \\
\text { inclinação para baixo do } \\
\text { balão com ar, reforçando o } \\
\text { entendimento de que é o ar } \\
\text { contido no balão que } \\
\text { diferencia o peso. }\end{array}$ & $\begin{array}{l}\text { A atividade não pode ser } \\
\text { classificada de } \\
\text { experimentação, uma vez } \\
\text { que não estabelece e nem } \\
\text { estimula o controle de } \\
\text { variáveis, com ausência de } \\
\text { "tratamentos", } \\
\text { indicações para o registro e } \\
\text { a apresentação dos dados. }\end{array}$ & $\begin{array}{l}\text { Sendo uma atividade } \\
\text { destinada à comprovação } \\
\text { de "que o ar é matéria", } \\
\text { pouco acresce em conflitos } \\
\text { mentais que possam gerar } \\
\text { hipóteses e comparar as } \\
\text { variáveis envolvidas nos } \\
\text { resultados. Por } \\
\text { consequência, fortalece } \\
\text { uma teoria, mas não se } \\
\text { caracteriza como } \\
\text { experimentação. }\end{array}$ \\
\hline $\begin{array}{l}\text { Comprovação } \\
\text { do atrito }\end{array}$ & $\begin{array}{l}\text { Propõe-se a demonstrar } \\
\text { que o atrito possibilita a } \\
\text { formação de pequenos } \\
\text { campos magnéticos, sendo } \\
\text { aplicada a técnica da } \\
\text { eletrização de um balão de } \\
\text { festa com lã para atrair } \\
\text { pedaços de papel. }\end{array}$ & $\begin{array}{l}\text { A atividade estimula o } \\
\text { estudante a observar um } \\
\text { fenômeno, mas não sugere } \\
\text { variáveis a serem } \\
\text { observadas, r e } \\
\text { posteriormente analisadas } \\
\text { por eles. }\end{array}$ & $\begin{array}{l}\text { Projeta o ato de observar } \\
\text { fenômenos } \\
\text { predeterminados, sem } \\
\text { gerar conflitos mentais } \\
\text { significativos no processo } \\
\text { de aprendizagem e } \\
\text { formação de conceitos. } \\
\text { Tampouco propõe } \\
\text { reestruturações de } \\
\text { percepções anteriores, na } \\
\text { ausência de conceitos e } \\
\text { entendimentos } \\
\text { necessários à melhor } \\
\text { interpretação } \\
\text { fenômeno estudado. do }\end{array}$ \\
\hline
\end{tabular}

Fonte: Autores

Partindo desse exemplo, concordamos que a experimentação propicia não só o desenvolvimento de habilidades técnicas dos estudantes; mas também de competências como reflexão e construção de generalizações sobre os fenômenos naturais, da capacidade de atuar em equipe e aplicar procedimentos para compreender os dados por eles obtidos em procedimentos investigativos, originários da interação dos estudantes com a realidade do seu universo (ARAÚJO; ABIB, 2003; ZÔMPERO; LABURÚ, 2011; NASCIMENTO; GOMES, 2018). Por meio da participação do estudante, aspectos das teorias são postos em prática para que o estudante se perceba como agente da construção do conhecimento científico. A ênfase ao termo "experimento" parece almejar a transformação de uma aula passiva em uma atividade dinâmica na qual os estudantes passarão a exercer investigações com criatividade e autonomia. Contudo, estaria claro para o estudante - e especialmente para o professor - que o ato de experimentar é mais complexo e envolve uma série de dimensões cognitivas e metodológicas próprias da problematização e investigação de fenômenos naturais?

É preciso explicitar nas atividades propostas em livros didáticos, roteiros de atividades práticas e sites educativos como a construção do conhecimento em atividades experimentais rompe fórmulas delimitadas, que preveem uma progressão inflexível do conhecimento. A própria ação de observar um fenômeno, um dos pressupostos do empirismo, demanda conhecimento sobre teorias pré-existentes, pois as concepções prévias dos atores do processo interferirão em seu modo de ver e de agir diante dos fatos observados (NASCIMENTO; GOMES, 
2008). Isto porque "o conhecimento científico cresce e evolui não por mera acumulação, mas principalmente por reformulação do conhecimento prévio" (MOREIRA; OSTERMANN, 1993, p. 115), quando as situações didáticas oportunizam superar obstáculos, identificados como estagnações e até regressões sobre conhecimentos que paralisam a apropriação de novos saberes, especialmente ao correlacionar causas e efeitos entre os fenômenos estudados (BACHELARD, 2007).

O estudante atua como um sujeito ativo, detentor de esquemas prévios conflitados na experimentação quando põe em dúvida as "verdades" estabelecidas previamente (BACHELARD, 2007). Para atingir este nível de abstração, o experimento necessita estar articulado com uma sequência didática estruturada por recursos e metodologias que subsidiem a aprendizagem com reinterpretações e acomodação das novas informações científicas evidenciadas na investigação (ZÔMPERO; LABURÚ, 2011; NASCIMENTO; GOMES, 2018). A experimentação, desta forma, contribui para desmistificar concepções de que a aprendizagem científica é incompatível com a prática cotidiana, da realidade que vivencia o sujeito aprendiz (CACHAPUZ; PRAIA; JORGE, 2004; CARVALHO, 2018). Se a transposição do conhecimento teórico para o prático se limitar a um roteiro fixo, o estudante não se habilitará a dar sentido ao que acontece em seu cotidiano, para compreensão da realidade à qual pertence.

Os conflitos cognitivos, que proporcionam novas "reequilibrações" nas estruturas responsáveis pela assimilação e acomodação de novos conhecimentos (CUNHA, 2004), ofertados ao estudante pela experimentação serão mais ricos se expostos aos colegas de forma a socializar dúvidas e problemas, o que amplia a formação de diversas hipóteses e confronto dos resultados obtidos. Neste aspecto, as atividades experimentais ajudam o estudante a expressar competências que sozinho talvez não consiga pôr em prática, mas pode, em interação com o outro (professor, colega de escola), aproximar-se do desenvolvimento potencial, assimilando e aplicando os conceitos científicos que agora constituem seu conhecimento (STRIEDER; WATANABE, 2018).

Entretanto, contrariando tais perspectivas, após análise de atividades didáticas experimentais (ADE) em livros didáticos aprovados pelo PNLD para o Ensino da Física (EF) e Ensino de Biologia (EB), Wesendonk, Rodrigues e Terrazan (2011) concluem:

não há praticamente $A D E$ para o EF e EB que apresentem um problema em que o aluno seja desafiado a resolver experimentalmente, o que faz com que estas ADE apenas contribuam para que os alunos adquiram uma visão de que o conhecimento científico é neutro, uma verdade já estabelecida e inquestionável, uma vez que a maior parte dessas atividades está proposta de modo a verificar um aspecto de um tópico conceitual já estabelecido no campo da Ciência (p. 14).

Seguimos, então, com o questionamento: Flexibilizar a terminologia ou transformar a natureza das atividades? O professor de Ciências necessita dispor de um variado repertório de atividades práticas, como a experimentação, que permitam reestruturar conhecimentos prévios, submetendo-os às representações mentais pré-existentes. Comumente, as atividades práticas contemplam a perspectiva do conhecimento estático e inquestionável reforçado em livros didáticos e sites educativos com propostas de atividades práticas em detrimento às 
considerações prévias dos estudantes, sem incorporar variações inerentes à realidade local, ou resultados diferentes dos esperados pelo professor (ZÔMPERO; LABURÚ, 2011).

Em parte como reconhecimento desta necessidade, a BNCC (BRASIL, 2018, p. 321) preconiza que uma das estratégias de investigação e compreensão dos fenômenos científicos está em planejar e realizar atividades de campo (experimentos, observações, leituras, visitas, ambientes virtuais etc.), de modo a facilitar os mecanismos inerentes à formação dos conhecimentos necessários para assimilar os conhecimentos científicos (SASSERON, 2018). Em seu entendimento sobre o ensino investigativo, o documento afirma que:

é preciso oferecer oportunidades para que eles [os estudantes], de fato, envolvam-se em processos de aprendizagem nos quais possam vivenciar momentos de investigação que lhes possibilitem exercitar e ampliar sua curiosidade, aperfeiçoar sua capacidade de observação, de raciocínio lógico e de criação, desenvolver posturas mais colaborativas e sistematizar suas primeiras explicações sobre o mundo natural e tecnológico, e sobre seu corpo, sua saúde e seu bem-estar, tendo como referência os conhecimentos, as linguagens e os procedimentos próprios das Ciências da Natureza (BRASIL, 2018, p. 329).

Deparamo-nos, então, com outro questionamento: Os aspectos positivos da experimentação justificariam "transformar" uma atividade prática observacional/ demonstrativa em um "experimento"? Como prerrogativa para adquirir um perfil experimental, a atividade prática deveria ser antecedida por questionamentos sobre as concepções prévias dos estudantes e pela formulação de hipóteses; necessitaria explicitar variáveis (mesmo que não necessariamente utilizando esta terminologia), e adotar preferencialmente uma abordagem quantitativa dos resultados, por exemplo, com apresentação destes em forma de tabelas e figuras, exploradas na análise dos resultados e na sua contextualização pelo experimentador. Alguns destes critérios são explorados em uma revisão sobre atividades práticas em coleções LD de Física e Biologia aprovados no PNLD (WESENDONK; RODRIGUES; TERRAZAN, 2011), o que se afirma viável a ser praticado.

Tomemos como exemplo uma atividade presente em sites educativos e em livros de ciências do ensino fundamental, de edições e coleções diferentes: ao apresentar o conteúdo de Botânica, propõe-se observar a germinação de sementes e acompanhar o crescimento da planta em direção à luz (Tabela 2). Trata-se de uma prática interessante de fácil execução que gera resultados visíveis ao auxiliar o estudante a entender que as plantas necessitam de radiação luminosa para sobreviver e crescer, seguindo em direção à luz por consequência da redistribuição dos hormônios de crescimento vegetal. A transformação desta atividade em uma experimentação seria alcançada elencando-se as variáveis a serem trabalhadas, como por exemplo, a variação da luminosidade no estudo do crescimento vegetal. Sem grandes custos adicionais, poderiam ser criados tratamentos, aplicando sobre as caixas faixas de luz diferentes (vermelha, verde e azul, por exemplo), tendo como controle a incidência da luz branca. Poderse-ia ainda trabalhar com variações da incidência de luz (de fraca, média ou alta intensidade), tendo como controle uma caixa sem exposição à luz, lugares com maior e menor sombra, quantificando a influência das variações de luz no crescimento e direcionamento da planta no sentido da luz em simulações com réplicas. 
Outra atividade comumente encontrada ao abordar o conteúdo "Solos" consiste na comparação da erosão de solos nus e cobertos com vegetação. Em linhas gerais, a atividade propõe comparar o deslocamento de partículas do solo (associado à erosão) disposto sobre bandejas levemente inclinadas quando exposto a uma "chuva" (com um regador manual ou mangueira). Dois tratamentos são comparados: solos com e sem vegetação. Ora, a "transformação" desta atividade em um experimento - com suas vantagens e dificuldades pode ser alcançada mediante uma inter-relação entre variáveis dependentes (velocidade de erosão, quantidade de solo deslocado, por exemplo) com variáveis independentes (tipo de solo, profundidade da bandeja, tipo de cobertura vegetal, nível de inclinação do suporte, intensidade do jato de água). Poder-se-ia aumentar a complexidade da atividade ao se propor a execução de repetições (réplicas) de cada tratamento, despertando a curiosidade do estudante para a possibilidade de variações dentro de um mesmo tratamento, além de comparar com a realidade que ocorre em desastres naturais provocados por deslizamentos em áreas íngremes. Assim, tal modificação não faria com que a proposta da atividade se aproximasse de forma mais contundente à realidade do estudante das práticas investigativas, reduzindo a distância entre o aprendiz e o cientista formulador das teorias?

Nas coleções e seus respectivos manuais do professor surpreende a ausência da natureza variável dos fenômenos naturais e até mesmo do erro como parte do procedimento de construção de conhecimento científico. Afinal, erros fazem parte do pensar cientificamente, já que o "errado" na concepção de uma ciência de conhecimento definitivo pode ser - para outra visão epistêmica - uma forma diferente de explicar o fenômeno quando flexibilizarmos a interpretação do mesmo (BACHELARD, 2007). Ao se aumentar a complexidade das práticas de ensino de Ciências, com a inserção de réplicas, por exemplo, a noção de variabilidade e erro pode ser trabalhada. Seria o caso de se questionar: ao buscar a iniciação científica do estudante os livros didáticos, roteiros avulsos repassados pelo professor e sites com propostas de atividades práticas deveriam alertar para a natureza falível da Ciência, preparando-o para possíveis "erros" ou formas diferentes de interpretar o mesmo fenômeno quando submetidos a experimentos?

O desafio consiste, então, ao professor transformar atividades demonstrativas em procedimentos experimentais, aumentando seu grau de complexidade e cientificidade (Tabela 3). Para isto, é necessário que ele esteja familiarizado com a terminologia e o corpo teórico da metodologia científica, consciente do propósito e da finalidade da experimentação. Trata-se de um desafio diante da formação atual recebida pelos professores recém-egressos dos cursos de licenciatura, os quais demonstram insegurança na condução de pesquisas didáticas (LIMA; VASCONCELOS, 2008). A maioria dos cursos de Licenciatura oferece limitadas oportunidades formais (por exemplo, em monografias de conclusão de curso) para o professor em formação conduzir pesquisa em sua área de atuação. Ou seja, não recebe uma formação condizente com os princípios da investigação científica, quando na verdade, o professor está diariamente exercendo seu papel de investigador em sala de aula, construindo e reconstruindo conhecimento.

Em um estudo recente envolvendo 210 professores de Ciências de diversos municípios de Pernambuco, Vasconcelos e Lima (2020) registraram divergências entre os procedimentos 
utilizados nas aulas práticas, com baixa frequência de realização de atividades investigativas. Problemas como a formação insuficiente nos cursos de graduação, deficiente infra-estrutura e limitações de carga horária foram citados como fatores impeditivos na realização de atividades experimentais e projetos de Feiras de Ciências Investigativas (VASCONCELOS; LIMA, 2020). 0 livro didático, então, pode contribuir para a superação destes obstáculos, ao veicular sugestões de experimentos factíveis, de baixo custo e adequados às realidades escolares brasileiras.

Estratégias metodológicas baseadas em atividades experimentais instigam nos estudantes a elaboração de conhecimentos particulares, não pré-determinados, mas inerentes ao processo de ensino e de aprendizagem. Contrapõem-se a metodologias valorativas e observações puras, comumente vivenciadas em aulas de laboratório e campo com práticas reprodutivistas que tendem a repetir conceitos abordados na aula teórica, negligenciando o processo de aprendizagem por descoberta (KRASILCHIK, 2004; LIMA, 2015). Teríamos, então, a necessidade de modificar ou flexibilizar as terminologias apresentadas nos livros didáticos, manuais de atividades práticas e sites com mesmo propósito educativo quando estes afirmam propor experimentos? Moreira e Ostermann (1993) defendem que é "preciso superar a visão de ciência que considera o processo de produção do conhecimento científico como uma rígida sequência de passos que começa com a observação e culmina em uma conclusão/descoberta" (p. 117). Portanto, é suscetível a falhas e a submissão da dúvida sobre seus resultados.

Se para o estudante a inadequação do termo experimento pode trazer confusões conceituais sobre a natureza da pesquisa científica, entendemos que para o professor as consequências podem ser igualmente lesivas. Mesmo utilizando uma prática chamada de "experimento", é necessário entender que um levantamento, uma observação ou uma demonstração seguem procedimentos diferentes e exigem abstrações e interpretações distintas dos saberes teorizados. Livros didáticos mais recentes têm evitado denominar atividades práticas do tipo construção de terrários, observação da biodiversidade na escola, entre outros, como experimentos. Aplicam, sim, o resgate de sua natureza e finalidade, denominando-a conceitualmente de observação, utilizando esta terminologia ao longo de toda a descrição da atividade. Ainda assim, é fundamental que a linguagem científica seja incorporada como subsídio da prática docente (e explicações adicionais poderiam vir no manual do professor), já que este exercerá sua capacidade investigativa de maneira mais eficiente se estiver familiarizado com a terminologia e o arcabouço metodológico por trás de cada atividade.

Tabela 3. Exemplos de transformação de uma atividade prática "não experimento" em um experimento com fins didáticos.

\begin{tabular}{llll}
\hline $\begin{array}{l}\text { Descrição } \\
\text { Atividade }\end{array}$ & da & $\begin{array}{l}\text { Indução de Possiveis } \\
\text { Problematizações }\end{array}$ & Possibilidades de Incorporação de Variáveis e Hipóteses \\
\hline Reciclagem de & Quais técnicas para o & Testar a resistência do papel produzido na reciclagem a \\
papel & preparo de papel partir de diferentes "matérias primas", comparar \\
& reciclado determinam diferentes tempos de imersão com água quente ou fria; \\
& maior resistência ao em outro tratamento adicionar substâncias como cola a \\
& papel produzido? Qual a base de goma ou látex, por exemplo. \\
& influência do tipo de \\
& papel na qualidade do \\
& produto final?
\end{tabular}




\begin{tabular}{|c|c|c|}
\hline $\begin{array}{l}\text { Percepção da } \\
\text { Temperatura }\end{array}$ & $\begin{array}{l}\text { Qual o grau de } \\
\text { percepção da variação } \\
\text { da temperatura captada } \\
\text { pelo tato em diferentes } \\
\text { partes do corpo? }\end{array}$ & $\begin{array}{l}\text { Avaliar se partes diferentes do corpo diferem quanto à } \\
\text { percepção da temperatura - morno e frio (aplicar na } \\
\text { palma da mão, nas costas da mão, na palma do pé etc.); } \\
\text { testar o efeito da presença de substâncias dissolvidas na } \\
\text { água na percepção da temperatura, variar a diferença de } \\
\text { temperatura, dentro de limites de segurança. }\end{array}$ \\
\hline $\begin{array}{l}\text { Crescimento } \\
\text { vegetal }\end{array}$ & \multicolumn{2}{|c|}{ Atividade já discutida no texto. } \\
\hline Erosão do solo & \multicolumn{2}{|c|}{ Atividade já discutida no texto. } \\
\hline $\begin{array}{l}\text { Propriedades do } \\
\text { ar }\end{array}$ & $\begin{array}{l}\text { Qual a diferenciação da } \\
\text { massa do ar em } \\
\text { condições diversas? }\end{array}$ & $\begin{array}{l}\text { Variar o tamanho dos balões e seu grau de enchimento; } \\
\text { utilizar barras de diferentes comprimentos e dispor os } \\
\text { balões a distâncias variáveis, comparar o esvaziamento } \\
\text { súbito e progressivo dos balões; aplicar o ponto de } \\
\text { equilíbrio entre as bexigas e avaliar a diferença da massa } \\
\text { do ar contida nas bexigas. }\end{array}$ \\
\hline $\begin{array}{l}\text { Comprovação } \\
\text { do atrito }\end{array}$ & $\begin{array}{lr}\text { Qual o grau de } \\
\text { eletrização de } & \text { bastões } \\
\text { constituídos } & \text { de } \\
\text { materiais } & \text { sólidos } \\
\text { diferentes? } & \\
\end{array}$ & $\begin{array}{l}\text { Testar bastões de madeira, aço, alumínio, porcelana, etc. } \\
\text { sendo atritado por tecidos de composições diversas: lã, } \\
\text { nylon, poliéster, algodão, etc. variando o tempo de atrito } \\
\text { e o peso e tamanho das partículas de papel a serem } \\
\text { atraídas. }\end{array}$ \\
\hline
\end{tabular}

Fonte: Autores

Em síntese, segundo Koponen e Mäntylä (2006), o papel epistemológico do experimento ainda necessita ser definido em sua complexidade uma vez que existe um amplo espectro de interpretações e usos deste procedimento no ensino de Ciências. Contudo, é inegável que a prática, como exercício de habilidades e técnicas, contribui para a formação de indivíduos críticos por propor um confronto entre verdades estabelecidas e verdades construídas, sob uma forma testável e falível. Ao analisar e interpretar resultados (frequentemente apropriando-se de recursos da Estatística), sustentados por teorias científicas, são propostas explicações, e os achados da pesquisa são apresentados em uma linguagem formal e comunicável, necessária para que um discurso seja aceito por outros sujeitos que compartilham dos mesmos rituais do discurso (FOUCAULT, 2008). Sendo assim, o produto do conhecimento científico é também uma articulação entre um conhecimento existente e a formação deste conhecimento na construção mental e nas representações do estudante.

\section{Conclusões}

Livros didáticos da educação básica e sites educativos veiculam propostas de atividades práticas apresentadas como experimentação cuja execução se esgota na confirmação de evidências, ao invés de oportunizar possibilidades ao estudante de questionar e propor hipóteses diante do fenômeno. Da mesma forma, ao final os resultados obtidos pela execução da atividade raramente os instigam a novas concepções, mas priorizam a simples constatação de que a ciência determina verdades inquestionáveis por outros que não sejam cientistas.

A partir desta reflexão, evidenciamos possibilidades de o professor ampliar o uso de propostas de atividades originalmente "não experimentais", tornando-as experimentos. Acreditamos que o professor tem autonomia e discernimento necessários para corrigir o uso inadequado do termo, se acreditar que isto evitará equívocos de aprendizagem entre os estudantes. Ao orientar o desenvolvimento de experimentos, é importante que o professor 
perceba outros fatores, tais como a adequação do estudo à realidade dos estudantes e às condições de infraestrutura, e os aspectos de segurança e ética. Por fim, cabe ao professor refletir sobre as diferenças de cada atividade prática sem uma "hierarquia" de validade, para que as diversas abordagens se complementem. Assim, busca-se evitar a percepção de que a construção do conhecimento científico ocorre sempre de forma linear e previsível. Com otimismo, observamos em nossa atividade diária de formação de professores do Ensino Básico e Superior o compromisso com uma postura cada vez mais investigadora, problematizadora e crítica do conhecimento veiculado nos livros e sites didáticos.

Nosso debate não pleiteia a experimentação como uma prática insubstituível, mas, sim, a que permite incorporar uma maior complexidade de competências. Defendemos o ensino de Ciências como um processo investigativo-reflexivo contínuo que exige do estudante a aplicação de outros conhecimentos e habilidades, alguns destes a serem aprendidos no decorrer do experimento, capacitando-os a questionar seus próprios resultados para ampliar suas percepções de mundo. Com a perspectiva de ensino-aprendizagem pela experimentação, espera-se que o estudante também vivencie etapas de descobertas e construções científicas.

\section{Agradecimentos}

Os autores agradecem ao Conselho Nacional de Desenvolvimento Científico e Tecnológico (CNPq), pela bolsa de produtividade e pelos recursos financeiros do Edital Universal 2016.

\section{Referências}

ABBAGNANO, N. Dicionário de Filosofia; 2 ed. São Paulo: Martins Fonseca, 1998.

ARAÚJO, M. S. T.; ABIB, M. L. V. S. Atividades experimentais no ensino de Física: diferentes enfoques, diferentes finalidades. Revista Brasileira de Ensino de Física, 25, 2, p.176-193, 2003.

BACHELARD, G. A Formação do Espírito Científico: contribuição para uma psicanálise do conhecimento. 7 ed. Rio de Janeiro: Contraponto, 2007.

BASSOLI, F. Atividades práticas e o ensino-aprendizagem de Ciência(s): mitos, tendências e distorções. Ciência \& Educação. v.20, n.3, p.579-593, 2014.

BRASIL, Base Nacional Comum Curricular: educação é a base. Brasília: Ministério da Educação e Cultura, 2018. Disponível em: basenacionalcomum.mec.gov.br/wp-content/.../2018/02/bncc20dez-site. Acesso em 02/2019.

BRASIL. Guia de livros didáticos: PNLD 2016: Ciências - Brasília: Ministério da Educação e Cultura, Secretaria de Educação Básica, 2016. Em www.mec.gov.br. Acesso em 01/2020

CACHAPUZ, A.; PRAIA, J.; JORGE, M. Da Educação em Ciências às orientações das ciências: um repensar epistemológico. Ciência \& Educação, 10, 3, p.363-381, 2004.

CARVALHO, A. M. P. Fundamentos Teóricos e Metodológicos do Ensino por Investigação. Revista Brasileira de Pesquisa em Educação em Ciências v. 18, n.3, p. 765-794, 2018. 
CUNHA, C. A. O papel do Conflito Sociocognitivo na aquisição da conservação de comprimento. Revista Psicologia em Estudo, v. 9, n. 1, p. 111-118, 2004.

FACHIN, O. Fundamentos de Metodologia Científica. São Paulo: Saraiva, 2017.

FERREIRA, A. B. H. Novo dicionário Aurélio da Língua Portuguesa. 4 ed., Curitiba: Positivo, 2009. FORD, E. D. Scientific Method for Ecological Research. Cambridge: University Press, 2000.

FOUCAULT, M. A Ordem do Discurso. 6 ed. São Paulo: Loyola, 2008.

GRAY, D.E. Pesquisa no Mundo Real. 2ä. ed., São Paulo: Ed. Penso, 2012.

HAEFNER, L. A.; ZEMBAL-SAUL, C. Learning by doing? Prospective elementary teachers' developing understandings of scientific inquiry and science teaching and learning. International Journal of Science Education, v. 26, n. 13, p. 1653-1674, 2004.

HODSON, D. Experiments in science and science teaching. Educational Philosophy and Theory v. 20, n. 2, p. 53-66, 1988.

HODSON, D. In search of a meaningful relationship: an exploration of some issues relating to integration in science and science education. International Journal of Science Education, v. 14, n. 5, p. 541-562, 1992.

KOPONEN, I. T.; MÄNTYLÄ, T. Generative role of experiments in Physics and in teaching Physics: a suggestion for epistemological reconstruction. Science and Education, v.15, n.1, p.31-54, 2006.

KRASILCHIK, M. Prática de Ensino de Biologia, 4 ed. São Paulo: Editora USP, 2004.

LIMA, K. E. C. Discurso de professores e documentos sobre o experimento do CECINE (Centro de Ensino de Ciências do Nordeste) nas décadas de 1960 e 1970. Tese de Doutorado do programa de Pós-Graduação em Educação da Universidade Federal de Pernambuco, 2015, t230 f.

LIMA, K. C.; VASCONCELOS, S. D. O Professor de Ciências das escolas municipais de Recife e suas perspectivas de educação permanente. Ciência \& Educação, v. 14, n. 2, p. 345- 362, 2008.

MILLAR, R. The role of practical work in the teaching and learning of science. High School Science Laboratories: Role and Vision, National Academy of Sciences, Washington, DC, p. 1-25 2004.

MOREIRA, M. A.; OSTERMANN, F. Sobre o ensino do método científico. Caderno Catarinense de Ensino de Física, 10, 2, p.108-117, 1993.

MURPHY, C., MURPHY, C.; KILFEATHER, P. Children making sense of Science. Research in Science Education, v. 41, n. 2, p. 283-298, 2011.

NARDI, R. Memórias da educação em Ciências no Brasil: a pesquisa no ensino de Física. Investigações em Ensino de Ciências, 10, 1, p.63-101, 2005.

NASCIMENTO, R. D.; GOMES, A. D. T. A Relação entre o Conhecimento Conceitual e o Desempenho de Estudantes em Atividades Investigativas. Revista Brasileira de Pesquisa em Educação em Ciências. v.18, n.3, p.935-965, 2018. 
OLIVEIRA, R. J. A crítica ao verbalismo e ao experimentalismo no ensino de Química e Física. Química Nova, 15, 1, p.86-89, 1992.

PÉREZ, M. Del C. B.; FURMAN, M. What is a Scientific Experiment? The Impact of a Professional Development Course on Teachers' Ability to Design an Inquiry-Based Science Curriculum. International Journal of Environmental \& Science Education, v. 11, n.6, p. 1387-1401, 2016.

SASSERON, L. H. Ensino de Ciências por Investigação e o Desenvolvimento de Práticas: Uma Mirada para a Base Nacional Comum Curricular. Revista Brasileira de Pesquisa em Educação em Ciências v. 18, n.3, p. 1061-1085, 2018.

STRIEDER, R. B.; WATANABE, G. Atividades Investigativas na Educação Científica: Dimensões e Perspectivas em Diálogos com o ENCl. Revista Brasileira de Pesquisa em Educação em Ciências. v.18, n.3, p. 819-849, 2018.

VASCONCELOS, S. D.; LIMA, K. E. C. Concepções de Professores da Rede Pública de Pernambuco sobre Feiras de Ciências: Reflexões a partir de uma Atividade Lúdica Revista Brasileira de Ensino de Ciências e Matemática, v.3, n.2, p.488-518, 2020.

VENDRUSCOLO, A. E. P. A experimentação numa perspectiva de projetos integradores. In: A. C. PAVÃO; D. FREITAS (Orgs.), Quanta Ciência Há no Ensino de Ciências. São Carlos: EDUFSCar, 2008, p.101-107.

WEISS, P. Experience and experiment in Biology. Does blind probing threaten to displace experience in biological experimentation? Science, 136, p.468-471, 1962.

WESENDONK, F. S.; PEREIRA, A. S.; TERRAZAN, E. A. Atividades Experimentais de Física e Química em Livros Didáticos do PNLD. Ensino de Ciências e Tecnologia em Revista, Vol. 1, n. 2, p.7-15, 2011.

ZÔMPERO, A. F.; LABURÚ, C. E. Atividades Investigativas no Ensino de Ciências: aspectos históricos e diferentes abordagens. Ensaio: Pesquisa em Educação em Ciências, v. 13, n. 3, p. 67-80, 2011. 